\title{
'When we assume ...'
}

\section{A commentary on the assumptions underlying the empowerment approach to diabetes care and education}

I welcome the opportunity to comment on the thought provoking article about the assumptions underlying the empowerment approach in this issue. ${ }^{1}$ I will discuss each assumption below.

First, the $\operatorname{article}^{1}$ asserts that the empowerment approach assumes '... that all or even most health care professionals (HCPs) ... are themselves able, willing and consciously in favour of dropping the traditional medical model ... for the opportunity to work as equal partners with their patients'. ${ }^{1}$ In our article ${ }^{2}$ about the barriers adopting the empowerment approach we discuss the deep hold of the traditional medical approach on most HCPs and the challenges of adopting a new paradigm.

Second, the empowerment approach assumes that '... the role of HCPs is simply (my emphasis) seen as helping patients acquire the knowledge and skills necessary to make well informed choices about their diabetes selfmanagement. ${ }^{\prime}$ Actually, the empowerment approach is much more patient-centered and collaborative. What we stated in the article cited ${ }^{3}$ was 'the role of the health professional is to help patients make informed decisions to achieve their goals and overcome barriers through education, appropriate care recommendations, expert advice and support.'

Third, the empowerment approach assumes that ' $\ldots$ responsibility for these patients' health outcomes lies fully and wholly with patients themselves.' While we believe that patients are responsible for the consequences of their decisions a variety of people such as policy makers, insurers, health professionals, employers and family members also make decisions that can affect patients' health outcomes. The quote used to support the above assertion is professionals need to give up feeling responsible for their patients'. ${ }^{1}$ Rather, we advocate that 'professionals need to give up feeling responsible for their patients and become responsible to them. Diabetes care then becomes a collaboration between equals.?

Fourth, the empowerment approach assumes '... that HCPs have communicated information about diabetes care in such a way ... that patients/ recipients ... can receive it successfully, understand it well and remember it ... patients and HCPs alike will have a sound knowledge base ... and will ... be equal partners in the decision making about diabetes self-care. ${ }^{11}$ Although we believe this is desirable, we do not suggest it reflects the way things are now. Empowerment is a work in progress, which is why we devote our time to improving education, providing professionals with the knowledge and skills to employ the empowerment approach and, through articles, promoting its adoption., ${ }^{2,4-9}$

Fifth, the empowerment approach assumes '.. that once communicated, knowledge relating to self-care will be understood and remembered by patients.' We believe that short-term interventions do not usually produce long-term results, which is why our recent research focuses on the development of long-term self-management support systems. ${ }^{4,9}$

Sixth, we agree with the authors' description of the problems associated with patients' faulty memories and cognitive deficits, but these problems are not unique to empowerment, they pose barriers to effective health care, no matter what approach is used.

Seventh, the empowerment approach assumes that '... the patient is able and willing to take on responsibility for their diabetes and be an equal partner in the decision making surrounding the management of their illness'. Empowerment is patientcentered care: providing patients with what they want and need. We encourage patients to tell us about aspects of the self-management plan that did not fit well with their lifestyle and we view discussion of possible revisions as collaborative care.

Robert M Anderson Ed D

Professor, University of Michigan

Medical School , USA

\section{References}

1. Asimakopoulou KG. Empowerment in the self-management of diabetes: are we ready to test assumptions? Eur Diabetes Nursing 2007; 4(3): 94-97.

2. Anderson RM, Funnell MM. Patient empowerment: reflections on the challenge of fostering the adoption of a new paradigm. Patient Educ Couns 2005; 57: 153-157.

3. Funnell MM, Anderson RM. Empowerment and self-management of diabetes. Clinical Diabetes 2004; 22(3): 123-127.

4. Funnell MM, Nwankwo R, Gillard ML, et al. Implementing an empowerment-based diabetes self-management education program. Diabetes Educ 2005; 31 (1): 53-61.

5. Anderson RM, Funnell MM. The Art of Empowerment: Stories and Strategies for Diabetes Educators, 2nd Edition. Alexandria, VA: American Diabetes Association, 2005.

6. Anderson RM. Patient empowerment and the traditional medical model: A case of irreconcilable differences? Diabetes Care 1995; 18(3): 412-415.

7. Glasgow RE, Anderson RM. In diabetes care, moving from compliance to adherence is not enough: Something entirely different is needed. Diabetes Care 1999; 22(12): 2090-2092.

8. Funnell MM, Anderson RM. Patient empowerment: A look back, a look ahead. Diabetes Educ 2003; 29(3): 454-462.

9. Tang TS, Gillard ML, Funnell MM, et al. Developing a new generation of ongoing diabetes self-management support interventions (DSMS): A preliminary report. Diabetes Educ 2005; 31(1): 91-97. 